\title{
PERSEPSI WISATAWAN TERHADAP OBJEK DAYA TARIK WISATA DI PANTAI KETAPANG, KABUPATEN PESAWARAN, PROVINSI LAMPUNG
}

\section{PERCEPTION OF TOURISTS TO THE TOURISM ATTRACTION OBJECT IN KETAPANG BEACH, PESAWARAN DISTRICT, LAMPUNG PROVINCE}

\author{
Ahmad Agung Prayitno*, Gunardi Djoko Winarno, Rusita, \\ Sugeng Prayitno Harianto ${ }^{1}$ \\ Jurusan Kehutanan, Fakultas Pertanian, Universitas Lampung \\ Jl. Prof. Dr. Soemantri Brojonegoro No 1, Bandar Lampung 35145 Indonesia \\ Email: ahmadagung3099@gmail.com
}

\begin{abstract}
ABSTRAK
Persepsi wisatawan terhadap suatu objek dan daya tarik wisata merupakan hal yang sangat penting karena dapat memberikan masukan bagi pengelola dalam pengembangan suatu objek dan daya tarik wisata. Penelitian ini bertujuan untuk mengetahui persepsi wisatawan terhadap objek dan daya tarik wisata, infrastruktur, fasilitas serta pelayanan yang ada di Pantai Ketapang menggunakan metode kuesioner tertutup. Hasil penelitian ini menunjukkan bahwa Pantai Ketapang memiliki enam objek dan daya tarik wisata yaitu keindahan sunrise/sunset, kejernihan air, pasir putih yang mengelilingi pantai, pasir timbul yang menghubungkan ke Pulau Mahitam, outbound dan camping ground serta souvenir. Nilai persepsi wisatawan pada aspek ODTW tertinggi yaitu outbound dan camping ground sedangkan nilai persepsi paling rendah terdapat pada souvenir untuk wisatawan yang tergolong dalam kategori cukup. Persepsi wisatawan terhadap fasilitas dan pelayanan berada lebih tinggi dibandingkan infrastruktur dan berada dibawah ODTW. Pengembangan perlu dilakukan pada perlebaran akses jalan utama dan penambahan pembatas jalan serta memperluas area parkir, objek dan daya tarik wisata yang lebih banyak dan beragam, lebih memperkenalkan Pantai Ketapang kepada masyarakat lokal.
\end{abstract}

Kata kunci : Wisata bahari, persepsi, wisatawan, wisata, obyek daya tarik wisata

\begin{abstract}
The perception of tourists towards a tourist attraction object is very important because it can offer some advices to managers for developing it. This study aims to see tourist's perceptions of tourist attractions object, infrastructure, facilities and services on Ketapang Beach using the Closed Questionnaire Method. The results showed that Ketapang Beach had six tourist attractions, namely the beauty of sunrise / sunset, the clarity of clean water, the white sand that surrounds the beach, embossed sand, outbound, camping ground and souvenirs. The highest tourist's perception score for tourist's attraction object was outbound and camping ground categories, while the lowest value for tourist perception score was the available of souvenirs which was in the sufficient category. Tourist perceptions of facilities and services were higher right under the Infrastructure and ODTW. The development is needing especialy on fixing road access and adding roadblock and also expanding the parking area, adding more kind of tourist attraction object, and introducing Ketapang Beach to the local community.
\end{abstract}

Keywords : Marine tourism, perceptions, tourists, tours, tourist attractions

\section{PENDAHULUAN}

Sektor pariwisata disebut sebagai salah satu sektor terbesar kedua dan terkuat dalam perekonomian dunia (Sofiyan et al., 2019). Objek wisata atau lebih dikenal dengan istilah daya tarik wisata atau "tourist attraction" adalah segala sesuatu yang dilihat wisatawan dan menjadi daya tarik untuk mengunjungi suatu daerah tertentu. Daya tarik wisata merupakan aspek paling utama yang memotivasi wisatawan untuk mengunjungi 
tempat tertentu dan juga menjadi fokus orientasi bagi pembangunan wisata terpadu (Triyono et al., 2018).

Persepsi wisatawan terhadap suatu objek wisata sangat penting untuk diketahui sehingga pengelola mendapatkan informasi untuk pengembangan dalam objek dan daya tarik wisata bahari (Prasetyo et al., 2019). Menurut Febryano et al. (2018) apabila pengembangan wisata sudah terpenuhi maka akan memberikan pengaruh kepuasan pengunjung dan juga minat untuk berkunjung kembali. Penelitian Utama et al. (2012) menyatakan bahwa persepsi wisatawan terhadap kebersihan keamanan objek dan daya tarik tersebut harus lebih diperhatikan untuk kenyamanan pengunjung. Hal ini sejalan dengan penelitian Widyasmara et al. (2013) menjelaskan bahwa persepsi merupakan proses dalam menentukan, mengorganisasi dan membagikan informasi untuk menciptakan gambaran dunia yang memiliki arti.

Penelitian mengenai persepsi wisatawan terhadap Objek dan Daya Tarik Wisata (ODTW) di lokasi penelitian belum pernah dilakukan sehingga penelitian ini penting dilakukan sebagai langkah awal dalam pengembangan objek dan daya tarik wisata yang berada di lokasi tersebut. Tujuan penelitian yaitu untuk mengetahui pengaruh objek dan daya tarik wisata, infrastruktur dan fasilitas layanan terhadap kepuasan pengunjung. Hasil dari penelitian ini dapat dijadikan bahan referensi dalam rencana pembangunan Pantai Ketapang yang lebih baik untuk ke depannya.

\section{METODE PENELITIAN}

Penelitian ini dilaksanakan pada bulan November-Desember 2020 di Pantai Ketapang yang secara administratif termasuk dalam Kabupaten Pesawaran, Provinsi Lampung. Objek yang diteliti yaitu persepsi wisatawan terhadap objek dan daya tarik wisata pantai, infrastruktur, fasilitas dan pelayanan yang berada di Pantai Ketapang. Peralatan yang digunakan yaitu: kamera (Digital/Handphone), GPS, laptop, aplikasi Arc Gis 10, Microsoft Excel, dan kuesioner untuk wisatawan. Peta lokasi penelitian ini bisa dilihat pada Gambar 1.

Pengumpulan data pada penelitian ini dilakukan dengan observasi dan wawancara langsung. Pengambilan sampel responden pengunjung dilakukan menggunakan metode random sampling dengan responden sebanyak 100 orang. Responden dihitung berdasarkan Rumus Slovin dengan error level 10\% (Sugiyono, 2014; Denada, et al., 2020).

$$
n=\frac{N}{1+N(e)^{2}}
$$

Jumlah responden Pantai Ketapang

$$
n=\frac{7.206}{1+7.206(0,1)^{2}}=100 \text { responden }
$$

Keterangan : $\mathrm{n}=$ Jumlah sampel; $\mathrm{N}=$ Jumlah populasi; e = error level

Kuesioner yang diberikan kepada responden berupa kuesioner tertutup yang berisi pernyataan-pernyataan mengenai pengelolaan wisata yang berada di Pantai Ketapang dengan empat aspek yaitu objek dan daya tarik wisata dengan enam indikator pernyataan yang meliputi keindahan sunset/sunrise, kejernihan air, pasir putih, outbound dan camping ground, pasir timbul dan souvenir; infrastruktur dengan enam indikator pernyataan meliputi, jalan utama, lahan parkir, jaringan telekomunikasi, pengelolaan dermaga, ketersediaan air bersih, tempat sampah dan kebersihan pantai; fasilitas dan pelayanan dengan delapan indikator meliputi, pengelolaan tempat wisata, ketersediaan gazebo, mushola, toilet umum, kantin dan warung, keramahan pengelola, papan informasi dan guide.

Penilaian yang ada disetiap indikator menggunakan acuan penilaian Skala Likert. Skala Likert merupakan suatu alat ukur untuk mengetahui persepsi individu atau sekelompok orang tentang fenomena sosial yang terjadi (Sugiyono, 2007; Nurbaiti et al., 2020). Penilaian tersebut menggunakan bobot penilaian Skala Likert yang dapat dilihat pada Tabel 1.

Rumus yang digunakan untuk perhitungan dalam Skala Likert ini kemudian dianalisis menggunakan Microsoft Excel dengan tiga tahapan sebagai berikut:

Perhitungan Scoring Skala Likert yang dapat dihitung dengan dengan rumus:

$$
\mathrm{NL}=\sum_{4)+\left(\mathrm{n}_{5} \times 5\right)}\left(\mathrm{n}_{1} \times 1\right)+\left(\mathrm{n}_{2} \times 2\right)+\left(\mathrm{n}_{3} \times 3\right)+\left(\mathrm{n}_{4} \times\right.
$$

Keterangan : NL = nilai scoring Skala Likert; $\mathrm{n}=$ jumlah jawaban score.

Perhitungan rata-rata tiap indikator pernyataan dapat dihitung menggunakan rumus: 


$$
\mathrm{Q}=\mathrm{NL} / \mathrm{X}
$$

Keterangan : $\mathrm{Q}=$ rata-rata aspek pernyataan ke-I; $\mathrm{NL}=$ nilai scoring Skala Likert; $\mathrm{x}=$ jumlah sampel responden

Perhitungan nilai akhir setiap indikator pernyataan dapat dihitung menggunakan rumus:

$$
\mathrm{NA}=\frac{\mathrm{Q} 1+\mathrm{Q} 2+\mathrm{Q} 3+\mathrm{Q} 4 \ldots \mathrm{Qp}}{p}
$$

Keterangan : NA = nilai akhir; Qp = ratarata tiap aspek pernyataan; $\mathrm{p}=$ jumlah seluruh pernyataan

Tabel 1. Bobot Nilai Skala Likert

\begin{tabular}{cc}
\hline Pernyataan & Nilai \\
\hline Sangat Tidak Setuju & 1 \\
Tidak Setuju & 2 \\
Netral & 3 \\
Setuju & 4 \\
Sangat Setuju & 5 \\
\hline
\end{tabular}

Sumber : Sugiyono (2014)

\section{HASIL DAN PEMBAHASAN}

Provinsi Lampung merupakan salah satu provinsi yang memiliki kekayaan sumber daya alam baik lautan maupun daratan yang terdiri dari sektor perikanan, pariwisata, perkebunan, pertanian, pertambangan, kehutanan, maupun peternakan (Sari et al., 2015). Wisata bahari yang berada di Provinsi Lampung memiliki potensi untuk terus dikembangkan karena terdapat dua teluk diantaranya Teluk Semaka dan Teluk Lampung yang terdapat sekitar 32 pulau didalamnya yang langsung berhadapan dengan ALKI (Arus Lintas Kapal
Internasional) selat sunda yang memiliki garis pantai sekitar $11.105 \mathrm{~km}$ (Rahman et al., 2021). Selain itu, potensi atraksi wisata yang berada di Lampung sangat mendukung dengan kondisi pantainya yang landai, atraksi ikan lumba-lumba, terumbu karang, keindahan sunset/sunrise dan atraksi lainnya baik dari alam maupun buatan (Abdillah, 2016). Menurut Rahman et al. (2021) dalam penelitiannya menjelaskan wisata bahari seperti ini banyak mendatangkan wisatawan pada setiap tahunnya dengan tingkat kunjungan yang terus meningkat dalam tiga tahun terakhir seperti peningkatan yang signifikan terjadi pada tahun 2016 ke tahun 2017 kurang lebih mencapai 4 juta pengunjung wisata datang ke Provinsi Lampung.

Pantai Ketapang merupakan salah satu pantai yang terletak di Kabupaten Pesawaran, Provinsi Lampung. Pantai ini memiliki letak pantai yang strategis dan berdekatan dengan Pulau Mahitam sehingga wisatawan banyak yang berkunjung. Konsep wisata bahari Pantai Ketapang didasarkan pada view (pemandangan), kejernihan air, pasir putih yang mengelilingi garis pantai, pasir timbul yang menghubungkan antara Pantai Ketapang dan Pulau Mahitam yang bisa dilewati pada saat air surut, keindahan sunset dan sunrise juga tidak kalah menarik serta area yang luas sehingga cocok digunakan sebagai outbound dan camping ground. Hal ini didukung oleh penelitian Anisa et al. (2018) yang menyatakan bahwa diperlukan area yang luas untuk digunakan saat kegiatan outbound dan camping agar tidak saling terganggu dengan kegiatan yang sedang berlangsung.

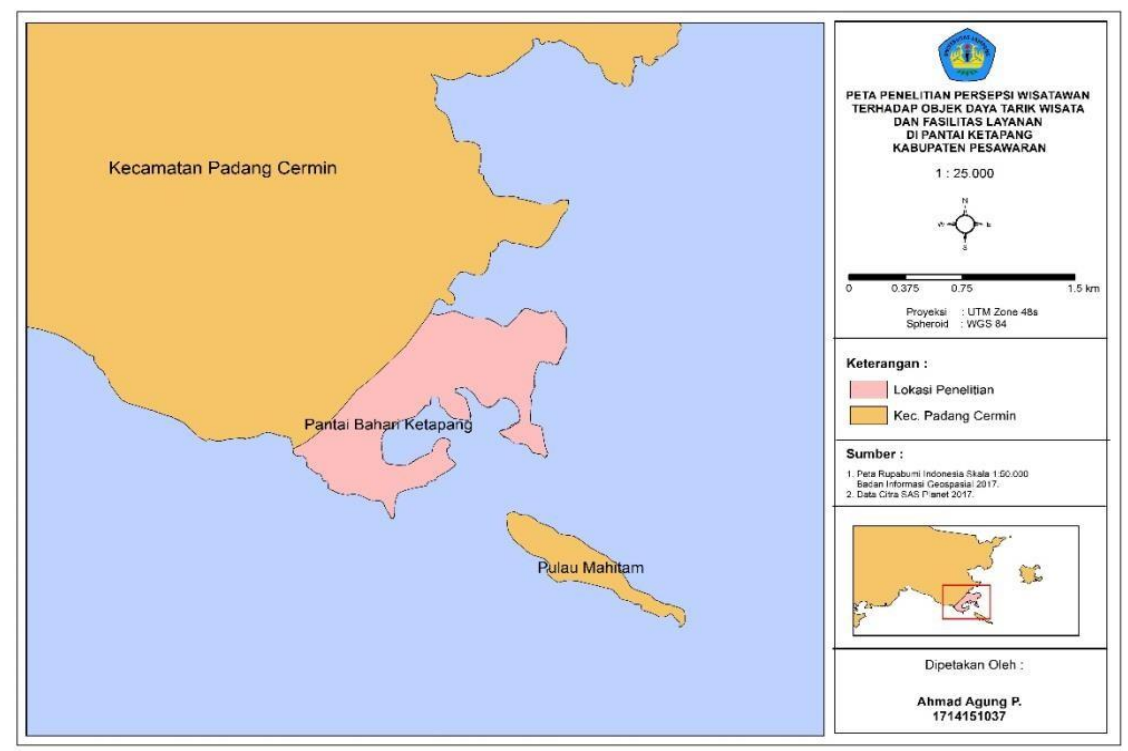

Gambar 1. Peta Lokasi Penelitian 


\section{Distribusi Wisatawan Berdasarkan Jenis} Kelamin dan Usia

Usia responden dibagi menjadi tiga kategori berdasarkan Depkes RI (2009) yaitu remaja, dewasa, dan lanjut usia. Karakteristik responden berdasarkan jenis kelamin dan usia disajikan dalam Tabel 2 . Wisatawan berjenis kelamin perempuan terutama golongan remaja dengan usia $<25$ tahun sangat mendominasi dalam memberikan penilaian, sedangkan penilaian tertinggi dari jenis kelamin laki-laki juga berasal dari golongan remaja. Wisatawan yang berusia 17-25 tahun dengan kategori remaja merupakan usia yang masih produktif sehingga berpengaruh terhadap pengambilan keputusan untuk berwisata. Karakteristik berdasarkan jenis kelamin dan usia dapat mempengaruhi penilaian persepsi. Tingkat pendidikan dan usia sangat berpengaruh dalam keputusan berwisata karena berhubungan dengan rasa ingin tahu yang tinggi untuk melihat atau mempelajari keunikan-keunikan yang ada (Keliwar, et al., 2015).

Tabel 2. Karakteristik wisatawan menurut jenis kelamin dan usia

\begin{tabular}{ccccc}
\hline \multicolumn{5}{c}{ Usia Responden } \\
\hline Kategori & Rentang Usia & $\mathrm{L}$ & $\mathrm{P}$ & Total \\
\hline Remaja & $<25$ & 30 & 34 & 64 \\
Dewasa & $25-45$ & 21 & 12 & 33 \\
Lansia & $>45$ & 2 & 1 & 3 \\
\hline \multicolumn{2}{c}{ Jumlah } & 53 & 47 & 100 \\
\hline
\end{tabular}

\section{Karakteristik Wisatawan Berdasarkan Daerah Asal Pengunjung}

Penilaian karakteristik pengunjung berdasarkan asal daerahnya dibagi menjadi delapan Kategori yaitu Lampung Tengah, Menggala, Bandar Lampung, Lampung Selatan, Jawa Barat, Natar, Pesawaran dan Lampung Timur yang akan disajikan pada Tabel 3. Sebagian besar responden yang berkunjung berasal dari daerah Bandar Lampung dengan persentase sebanyak 30\%, kemudian pengunjung yang berasal dari Lampung Tengah lalu Lampung timur dengan persentase masing-masing $15 \%$ dan $14 \%$. Wisatawan yang berasal dari luar Provinsi Lampung yaitu ada sebanyak $7 \%$ dari total keseluruhan responden. Wisatawan yang datang dari luar Lampung yaitu berasal dari Sukabumi, Jawa Barat dan Bekasi, Jawa Barat. Wisatawan yang berasal dari luar Lampung sangat sedikit karena mereka harus lebih menyiapkan rencana yang sangat matang untuk memenuhi kebutuhan selama berwisata seperti pengeluaran biaya, waktu dan pekerjaan.

Tabel 3. Karakteristik wisatawan menurut daerah asal pengunjung

\begin{tabular}{ccccc}
\hline \multicolumn{5}{c}{ Asal Daerah } \\
\hline No & Daerah & $\mathrm{L}$ & $\mathrm{P}$ & Total \\
\hline 1 & Lampung Tengah & 10 & 5 & 15 \\
2 & Menggala & 2 & 2 & 4 \\
3 & Bandar Lampung & 11 & 19 & 30 \\
4 & Lampung Selatan & 7 & 3 & 10 \\
5 & Jawa Barat & 4 & 3 & 7 \\
6 & Natar & 4 & 6 & 10 \\
7 & Pesawaran & 5 & 5 & 10 \\
8 & Lampung Timur & 10 & 4 & 14 \\
\hline 9 & Jumlah & 53 & 47 & 100 \\
\hline
\end{tabular}

\section{Persepsi Wisatawan di Pantai Ketapang Objek dan Daya Tarik Wisata}

Objek daya tarik wisata merupakan penggerak utama yang memotivasi wisatawan untuk berkunjung pada suatu tempat. Menurut pernyataan Triyono et al. (2018) bahwa daya tarik juga disebut menjadi fokus orientasi untuk pembangunan dan perencanaan wisata terpadu. Objek dan daya tarik wisata yang dapat dinikmati saat berkunjung ke Pantai Ketapang yaitu sunrise/sunset, air pantai yang jernih, pasir berwarna putih, outbound dan camping ground, pasir timbul, dan souvenir. Persepsi wisatawan terhadap objek dan daya tarik wisata dapat dilihat pada Gambar 2.

Outbound dan camping ground merupakan salah satu objek dan daya tarik wisata yang sangat diminati oleh para wisatawan sehingga memiliki nilai tertinggi diantara yang lainnya dengan nilai rata-rata 4,78 termasuk dalam kategori setuju. Hal ini didukung karena tempat yang sangat luas untuk melakukan kegiatan outbound dan camping. Pantai Ketapang ini mempunyai udara sejuk dibawah pohon kelapa yang berjajar disepanjang pantai dan biasanya digunakan untuk kegiatan outbound. Pernyataan tentang Keindahan sunset/sunrise dan juga pasir timbul yang dapat dinikmati wisatawan juga mendapatkan penilaian yang sangat tinggi dari wisatawan dengan ratarata 4 termasuk dalam kategori setuju. Menurut wisatawan yang berkunjung, ODTW yang ada di Pantai Ketapang ini sudah cukup baik dan hanya saja pada bagian souvenir yang dijual kurang diminati oleh pengunjung karena tidak identik dengan apa yang ada di Pantai Ketapang dengan nilai rata-rata yang didapatkan 3,09 termasuk dalam kategori Netral. 


\section{Infrastruktur}

Infrastruktur di Pantai Ketapang memiliki 6 indikator yang digunakan dalam penilaian persepsi yaitu jalan utama, tempat parkir, jaringan telekomunikasi, dermaga, air bersih, tempat sampah. Penilaian wisatawan terhadap infrastruktur di Pantai Ketapang dapat dilihat pada Gambar 3.

Jalan utama di Pantai Ketapang memiliki nilai rata-rata 3,23 dalam kategori cukup. Jalan utama pada persepsi infrastrktur mendapatkan penilaian netral karena akses jalan utama yang kurang lebar walaupun sudah di aspal. Menurut wisatawan seharusnya jalan utama menuju Pantai Ketapang sebaiknya diperluas dan diberi pembatas jalan.

Selanjutnya, tempat parkir yang tersedia di Pantai Ketapang mendapatkan penilaian dengan nilai rata-rata 3,79 termasuk dalam kategori netral. Hal ini karena masih kurang luasnya area untuk parkir, sehingga perlu dilakukan penambahan tempat parkir. Menurut Pauwah et al. (2013) menyatakan bahwa tempat parkir merupakan aspek yang sangat dasar dan penting untuk diperhatikan karena dapat mempengaruhi kunjungan wisatawan saat membludak ketika liburan.

Nilai tertinggi untuk infrastruktur terdapat pada ketersediaan jaringan telekomunikasi yang terjangkau dan sangat baik di area wisata dengan nilai rata-rata 4,53 termasuk dalam kategori setuju.
Penelitian yang dilakukan oleh Khasani et al. (2014) menunjukan bahwa daya tarik dan fasilitas akan tercapai dengan mudah apabila infrastruktur dasar seperti area parkir sudah memadai. Pengembangan infrastruktur yang ada di suatu daerah tidak hanya dinikmati oleh wisata yang berkunjung saja, tetapi juga dapat dinikmati oleh masyarakat yang tinggal di sekitar tempat wisata tersebut.

\section{Fasilitas dan Pelayanan}

Persepsi wisatawan terhadap fasilitas dan pelayanan yaitu mendapatkan nilai akhir sangat baik $(4,13)$, sehingga harus dijaga dan dirawat agar pengunjung lebih nyaman berwisata dengan fasilitas yang tersedia sangat lengkap. Fasilitas dan pelayanan di Pantai Ketapang memiliki 8 indikator yang digunakan dalam penilaian persepsi yaitu pengelolaan wisata, ketersediaan gazebo, mushola, toilet, keramahan pengelola, papan informasi, guide.. Penilaian wisatawan terhadap fasilitas dan pelayanan di Pantai Ketapang dapat dilihat pada Gambar 4.

Mushola yang berada di Pantai Ketapang mendapatkan nilai paling tinggi $(4,66)$ dengan tingkat perawatan paling bagus. Persepsi wisatawan tentang guide mendapatkan nilai rata-rata paling rendah yaitu 2,27 termasuk dalam kategori tidak setuju. Hal ini disebabkan karena kurangnya pelayanan dari guide untuk wisatawan yang datang dari Provinsi Lampung maupun luar Provinsi Lampung.

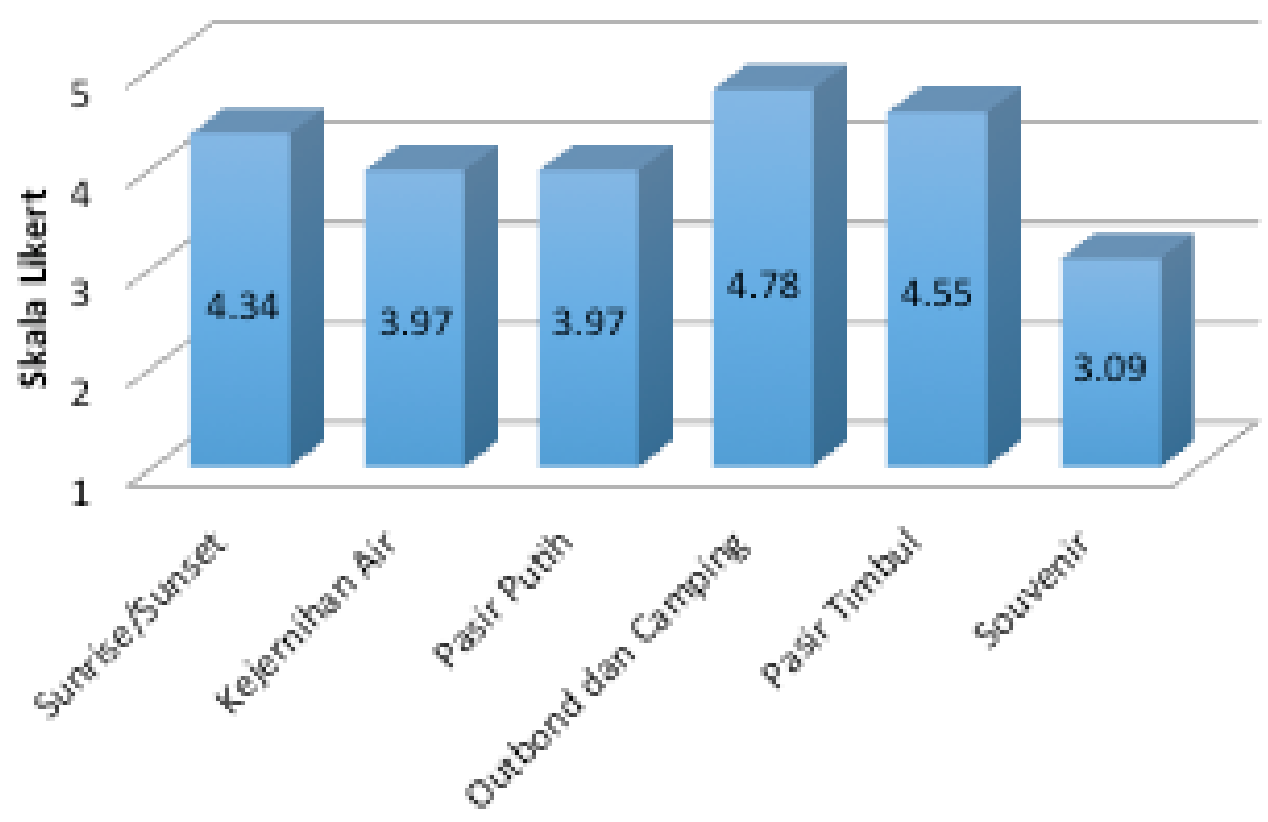

Gambar 2. Grafik persepsi wisatawan terhadap objek dan daya tarik wisata Keterangan penilaian persepsi : $1=$ sangat tidak setuju, $2=$ Kurang setuju, $3=$ Netral, $4=$ setuju, $5=$ sangat setuju 


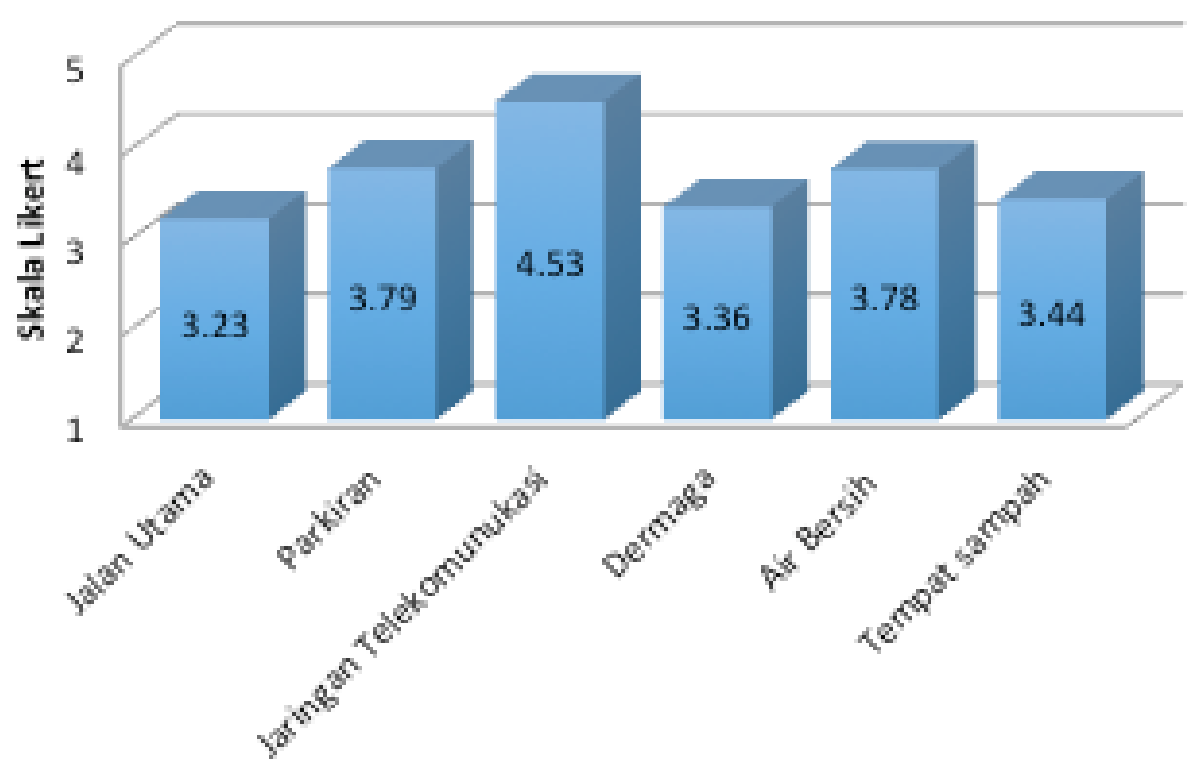

Gambar 3. Grafik persepsi wisatawan terhadap Infrastruktur Keterangan penilaian persepsi: $1=$ sangat tidak setuju, $2=$ Kurang setuju, $3=$ Netral, $4=$ setuju, $5=$ sangat setuju

Khotimah et al. (2017) menjelaskan bahwa pelayanan tambahan lebih kepada ketersediaan sarana dan fasilitas umum seperti bank, ATM, telekomunikasi, rumah sakit dan sebagainya penting adanya untuk mendukung wisatawan yang berkunjung agar lebih nyaman dan terfasilitasi. Selanjutnya Wahyulina et al. (2018) menyebutkan bahwa fasilitas seperti toilet, tempat sampah, dan tempat ibadah merupakan suatu hal yang paling penting untuk kenyamanan pengunjung. Hal ini juga diperkuat oleh penelitian wiradipoetra et al. (2018) bahwa fasilitas yang rusak akibat kurangnya perawatan dinilai sebagai pemicu persepsi negatif wisatawan terhadap objek dan daya tarik wisata, sehingga berdampak kurangnya minat untuk berkunjung ulang pada wisatawan.

\section{Perbandingan Nilai Persepsi Wisatawan}

Perbandingan nilai persepsi wisatawan sangat penting diketahui karena dapat membantu pengelola tempat wisata dalam pengembangan dan perencanaan pembangunan lokasi tersebut. Hasil perbandingan ini digunakan sebagai acuan pengelola dalam memperbaiki hal apa saja yang harus diutamakan, sehingga dari pengembangan yang telah dilakukan dapat membawa pengunjung yang lebih banyak lagi. Perbandingan nilai persepsi wisatawan terhadap objek dan daya tarik wisata, infrastruktur, fasilitas dan pelayanan dapat dilihat pada Gambar 5.
Perbandingan dari semua nilai akhir persepsi wisatawan diatas menunjukan bahwa ODTW $(4,32)$ dan Fasilitas Pelayanan $(4,13)$ yang dimiliki Pantai Ketapang sudah baik. Hal ini dapat terjadi karena Pantai Ketapang selalu meningkatkan Fasilitas dan Pelayanan yang ada untuk menarik wisatawan supaya datang berwisata. Objek dan daya tarik wisata yang ada di Pantai Ketapang juga memiliki nilai yang lebih tinggi, karena ditempat ini wisatawan dapat bersantai sambil menikmati sunrise/sunset serta melihat pasir timbul yang terlihat saat air sedang surut. Pasir timbul yang berada di Pantai Ketapang ini dapat digunakan sebagai akses penyebrangan menuju Pulau Mahitam. Penilaian persepsi wisatawan untuk pasir timbul ini mendapatkan nilai rata-rata yang tinggi yaitu 4,55 dan termasuk kedalam kategori setuju.

Nilai persepsi wisatawan paling rendah dengan nilai akhir 3,74 yaitu pada infrastruktur yang ada. Hal ini karena wisatawan menilai akses jalan utama yang masih sempit dan juga tidak adanya pembatas jalan untuk masuk kedalam pantai. Lahan parkir juga menjadi keluhan sebagian besar pengunjung yang datang, karena area parkir masih kurang luas untuk hari libur dan akhir pekan. Wisatawan masih banyak berharap kepada pengelola agar memperbaiki akses jalan utama dan memperluas area parkir yang tersedia. 


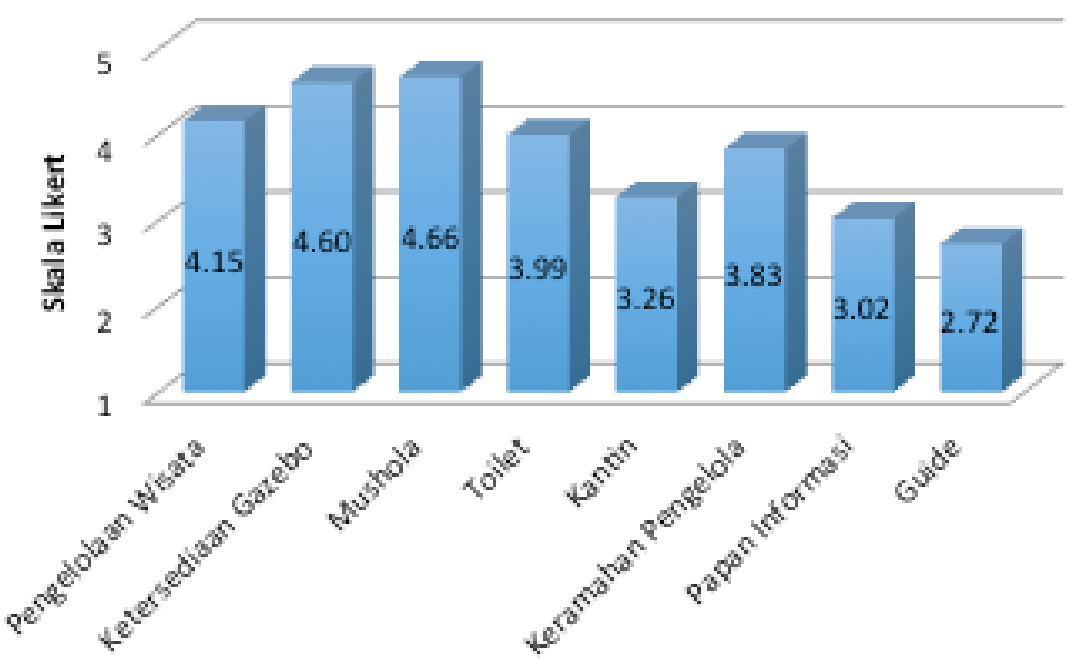

Gambar 4. Persepsi wisatawan terhadap Fasilitas dan Pelayanan di Pantai Ketapang Keterangan penilaian persepsi: 1 = sangat tidak setuju, $2=$ Kurang setuju, $3=$ Netral, $4=$ setuju, $5=$ sangat setuju

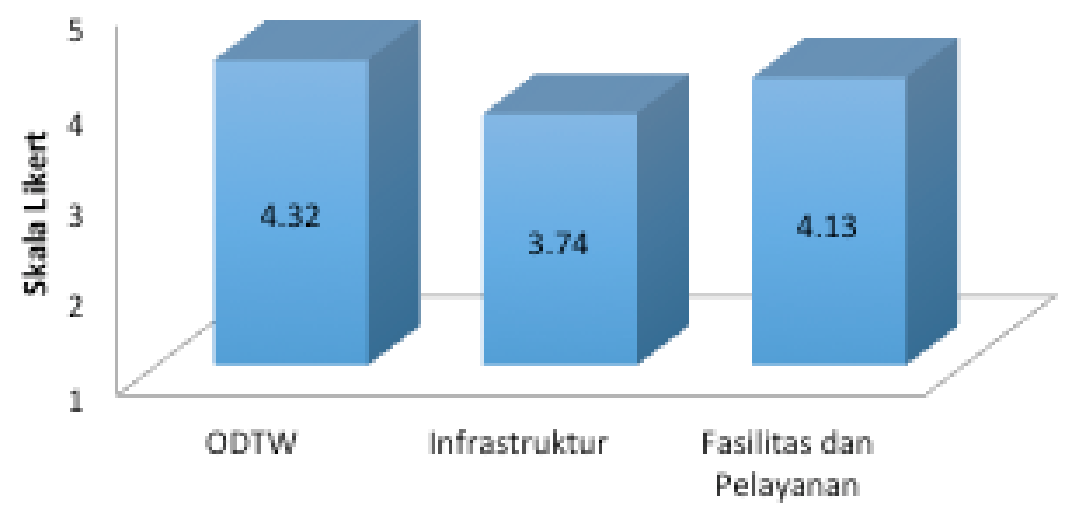

Gambar 5. Perbandingan nilai akhir persepsi terhadap ODTW, Infrastruktur, Fasilitas dan Pelayanan. Keterangan penilaian persepsi: 1 = sangat tidak setuju, 2 = Kurang setuju, $3=$ Netral, $4=$ setuju, $5=$ sangat setuju

\section{KESIMPULAN}

Pantai Ketapang memiliki enam objek dan daya tarik wisata diantaranya adalah keindahan sunrise/sunset, pasir putih yang mengelilingi pantai, pasir timbul, kejernihan airnya, outbound dan camping ground, dan souvenir. Nilai persepsi wisatawan yang paling tinggi terdapat pada outbound dan camping ground $(4,78)$, lalu disusul dengan keindahan sunsrise/sunset $(4,34)$ dan pasir timbulnya $(4,55)$. Skor terendah terdapat pada souvenir $(3,09)$, karena belum adanya cinderamata yang dijual atau diberikan kepada wisatawan saat berkunjung ke Pantai Ketapang. Infrastruktur yang ada di Pantai Ketapang memiliki nilai akhir paling rendah $(3,74)$ diantara ODTW $(4,32)$, Fasilitas dan
Pelayanan $(4,13)$. Pengelola perlu melakukan pengembangan, terutama pada akses jalan utama dan area parkir yang tersedia serta penambahan menu makanan yang berada di kantin. Pemasaran juga perlu ditingkatkan oleh pengelola pantai untuk melakukan kerja sama dengan agen pariwisata/perjalanan wisata, perguruan tinggi maupun sekolah serta membuat paket penginapan dan melibatkan tour guide untuk pengenalan pantai sehingga dapat menambah penghasilan yang ada di Pantai Ketapang.

\section{REFERENSI}

Abdillah, D. 2016. Pengembangan wisata bahari di Pesisir Pantai Teluk Lampung. Jurnal Destinasi Kepariwisataan Indonesia, 1(1):45-66. 
Anisa, R.F. \& Susilo, H. 2018. Pengaruh outbound training terhadap kinerja karyawan melalui motivasi sebagai variabel intervening (studi pada kantor pusat d'Besto, Pt Evalinda Berkah Mandiri). Jurnal Administrasi Bisnis, 60(1):203-210.

Depkes RI. 2009. Sistem Kesehatan Nasional. Jakarta. Departemen Kesehatan Republik Indonesia.

Denada, A.N.I., Winarno, G.D., Iswandaru, D. Fitriana, Y.R. 2020. Analisis persepsi pengunjung dalam pengelolaan lebah madu untuk mendukung kegiatan ekowisata di Desa Kecapi, Kalianda, Lampung Selatan. Jurnal Belantara, 3(2):153-162.

Febryano, I.G. \& Rusita. 2018. Persepsi wisatawan dalam pengembangan wisata pendidikan berbasis konservasi Gajah Sumatra (Elephas Maximus Sumatranus). Jurnal Pengelolaan Sumberdaya Alam dan Lingkungan, 8(3):376-382.

Keliwar, S. \& Nurcahyo, A. 2015. Motivation and perception visitor against tourist attractions pampang Cultural Village in Samarinda. Jurnal Manajemen Resort dan Leisure, 12(2):19-27.

Khasani, M.A. 2014. Analisis Faktor-Faktor yang Mempengaruhi Kunjungan Wisatawan di Pantai Cahaya Weleri Kabupaten Kendal. Skipsi. Semarang: Universitas Diponegoro.

Khotimah, K., Wilopo. \& Hakim, L. 2017. Strategi pengembangan destinasi pariwisata (studi kasus pada Kawasan Situs Trowulan sebagai pariwisata budaya unggulan di Kabupaten Mojokerto). Jurnal Administrasi Bisnis, 41(1):56-65.

Nugraha, B., Banuwa, I.S. \& Widagdo, S. 2015. Perencanaan lanskap ekowisata hutan mangrove di pantai sari ringgung desa Sidodadi Kecamatan Padang Cermin Kabupaten Pesawaran. Jurnal Sylva Lestari, 3(2):53-66.

Nurbaiti., Harianto, S.P., Iswandaru, D. \& Febryano, I.G. 2020. Persepsi pengunjung terhadap wisata bahari di Pantai Klara, Provinsi Lampung. Journal of Tropical Marine Science, 3(2):65-73.

Pauwah, Y., Kumurur, V.A., Sela, R.L.E. \& Rogi, O.H.A. 2013. Persepsi dan preferensi pengunjung terhadap Kawasan Wisata. Jurnal Unsrat, 5(1):22-27.

Prasetyo, D., Darmawan, A. \& Dewi, B.S. 2019. Persepsi wisatawan dan individu kunci tentang pengelolaan ekowisata di Lampung Mangrove Center. Jurnal Sylva Lestari, 7(1):22-29.

Rahman, A., Sumanjono, S. \& Meiliyana. 2021. Strategi pengembangan potensi pariwisata bahari Kabupaten Pesawaran (studi pada Pantai Ketapang Dalam/Cuku Upas Pesawaran). Jurnal Birokrasi, Kebijakan dan Pelayanan Publik, 3(1):111.

Saputra, E.S. \& Setiawan A. 2014. Potensi ekowisata hutan mangrove di Desa Merak Belatung Kecamatan Kalianda Kabupaten Lampung Selatan. Jurnal Sylva Lestari, 2(2):49-60.

Sari, Y., Yuwono, S.B. \& Rusita. 2015. Analisis potensi dan daya dukung sepanjang jalur ekowisata hutan mangrove di Pantai Sari Ringgung Kabupaten Pesawaran Lampung. Jurnal Sylva Lestari, 3(3):31-40.

Sofiyan, A., Hidayat, W., Winarno, G.D. \& Harianto, S.P. 2019. Analisi daya dukung fisik, rill, dan efektif ekowisata di Pulau Pisang Kabupaten Pesisir Barat. Jurnal Syvla Lestari, 7(2):225-234.

Sugiyono. 2014. Metode Penelitian Pendidikan Kuantitatif, Kualitatif dan R\&D. Bandung: Alfabeta. 464p.

Triyono, S., Damiasih. \& Sudiro, S. 2018. Pengaruh daya tarik dan promosi wisata terhadap kepuasan pengunjung kampoeng wisata di Desa Melikan Kabupaten Klaten. Jurnal Kepariwisataan, 12(1):29-40.

Utama, R.B.I.G. \& Mahadewi, E.N.M. 2012. Metode Pariwisata dan Perhotelan. Yogyakarta : CV. Andi Offset 238p.

Wahyulina, S., Darwini, S,. Retnowati, W. \& Oktaryani, S. 2018. Persepsi wisatawan muslim terhadap sarana penunjang wisata halal di Kawasan Desa Sembalun Lawang Lombok Timur. Jurnal Magister Manajemen Universitas Mataram, 7(1):27-39.

Widyasrama, I.B.M., Negara, I.M.K. \& Suardana. 2013. Persepsi wisatawan terhadap wisata pantai di Kelurahan Pecatu Kabupaten Badung dalam perencanaan paket wisata. Jurnal IPTA, $1(1): 45-50$.

Wiradipoetra, F.A. \& Brahmanto, E. 2016. Analisis persepsi wisatawan mengenai penurunan kualitas daya tarik wisata terhadap minat berkunjung. Jurnal Pariwisata, 3(2):133-137. 